CENDEKIA, Vol. 12, No. 1, April 2018

p ISSN: 1978 2098; e ISSN: 2407 8557

Http://cendekia.pusatbahasa.or.id; Email: cendekiaoslo@gmail.com

Center of Language and Culture Studies, Surakarta, Indonesia

Salam, Fuad Anis \& Heriyanto, Suwiro. 2018. Pengaruh Sertifikasi Guru dan Pengembangan

Karir terhadap Kepuasan Kerja Guru Akuntansi SMA di Kota Cilegon.

Cendekia, (2018), 12(1): 23 32. DOI: 10.30957/cendekia.v12i.434.

\title{
PENGARUH SERTIFIKASI GURU DAN PENGEMBANGAN KARIR TERHADAP KEPUASAN KERJA GURU AKUNTANSI SMA DI KOTA CILEGON
}

\author{
Anis Fuad Salam \& Suwiro Heriyanto \\ STIE Banten \\ Jl. Letnan Jidun No. 5C Kepandean, Serang Banten 4115 \\ Corresponding author: fuadiali71@gmail.com HP: 081314888882
}

\begin{abstract}
The purpose of this study is to know: 1) the effect of certification on the performance of accounting teachers in Senior High School (SMA) Kota Cilegon; 2) the influence of career development on the performance of high school accounting teachers in Cilegon City; 3) the influence of certification and career development together towards the performance of accounting teachers in SMA Kota Cilegon. The method used is a survey of all high school accounting teachers in Cilegon City. Number of samples counted 48 people. Based on the research results can be concluded: (1) There is a significant influence between teacher certification with job satisfaction of accounting teachers in Cilegon City; (2) there is a significant influence between career development with job satisfaction of accounting teacher in Cilegon City; and (3) there is a significant influence between teacher certification and career development on accounting teacher accounting satisfaction in Cilegon City.
\end{abstract}

Keywords: Certification, career development, job satisfaction

\section{PENDAHULUAN}

Rendahnya profesionalitas guru di Indonesia dapat dilihat dari kelayakan guru mengajar. Menurut Balitbang Depdiknas (2012), guru-guru yang layak mengajar untuk tingkat SD baik negeri maupun swasta ternyata hanya 28,94\%. Guru SMP negeri $54,12 \%$, swasta $60,99 \%$, guru SMA negeri $65,29 \%$, swasta $64,73 \%$, guru SMK negeri $55,91 \%$, swasta $58,26 \%$.

Kenyataan empiris menunjukkan bahwa, di kota Cilegon masih banyak guru yang belum berpendidikan S1, berarti mereka belum mampu memenuhi ketentuan Pasal 46 ayat 3 Undang-Undang Nomor 14 Tahun 2005 tentang Guru dan Dosen yang menyebutkan bahwa seorang guru harus memiliki kualifikasi akademik minimum S-1 atau D-4.

Rendahnya mutu guru juga dapat dilihat dari status guru yang mengajar. Masih banyak guru di Kota Cilegon yang statusnya masih honor murni (568 orang), honor daerah (340 orang), guru bantu dan guru kontrak (234 orang). 
CENDEKIA, Vol. 12, No. 1, April 2018

p ISSN: 1978 2098; e ISSN: 2407 8557

Http://cendekia.pusatbahasa.or.id; Email: cendekiaoslo@gmail.com

Center of Language and Culture Studies, Surakarta, Indonesia

Salam, Fuad Anis \& Heriyanto, Suwiro. 2018. Pengaruh Sertifikasi Guru dan Pengembangan

Karir terhadap Kepuasan Kerja Guru Akuntansi SMA di Kota Cilegon.

Cendekia, (2018), 12(1): 23 32. DOI: 10.30957/cendekia.v12i.434.

Hasil survei kinerja guru di Jawa Barat yang dirilis oleh Ikatan Guru Honorer (IGH) Jawa Barat menunjukkan bahwa: 1) kinerja guru secara umum masih rendah, 2) tidak ada perbedaan antara kinerja guru yang sudah disertifikasi dengan yang belum, 3) tidak ada beda yang signifikan antara kinerja guru berpendidikan S1 dan S2, 4) kinerja guru honorer jauh di bawah guru PNS, 5) kinerja guru usia di bawah 40 tahun lebih tinggi dibandingkan kinerja guru di atas 40 tahun, dan 6) guru yang menjagar mata pelajaran yang di UN kan lebih tinggi dibandingkan kinerja guru yang menggajat mata pelajaran tidak di UN kan (IGH Jabar, 2012).

Pada dasarnya masalah mutu guru dapat dikelompokkan menjadi dua kelompok besar, yaitu masalah yang bersumber pada sebab-sebab intern dan ekstren. Masalah yang bersumber dari sebab intern berasal dari guru itu sendiri yang sebenarnya berada dalam kemampuan guru untuk mengatasinya. Akan tetapi tidak demikian halnya dengan sebab-sebab ekstren, yaitu hal-hal yang berasal dari luar sistem pendidikan dan semuanya di luar kemampuan guru untuk mengatasinya. Hal inilah yang perlu mendapat perhatian dari kita semua, mulai dari pemerintah pusat, daerah, pengawas sekolah, hingga kepala sekolah.

Berdasarkan pemikiran di atas bahwa kinerja guru sangat mempengaruhi kegiatan pembelajaran, penulis tertarik untuk melakukan penelitian tentang kinerja guru akuntansi SMA yang diduga dipengaruhi oleh sertifikasi dan pengembangan karir.

\section{TINJAUAN PUSTAKA}

Kinerja adalah sesuatu yang dicapai atau prestasi yang diperlihatkan atau kemampuan bekerja, dengan kata lain kinerja dapat diartikan sebagai prestasi kerja. Kinerja atau performance merupakan hasil kerja yang dapat dicapai oleh seseorang atau sekelompok orang dalam suatu organisasi, sesuai dengan wewenang dan tanggung jawab masing-masing, dalam rangka upaya mencapai tujuan organisasi bersangkutan secara legal, tidak melanggar hukum dan sesuai dengan moral maupun etika. Kinerja individu adalah dasar kinerja organisasi, dan untuk memaksimalkan kinerja masingmasing individu, berhubungan dengan perilaku individu.

Kinerja merupakan terjemahan dari bahasa Inggris work performance atau job performance. Kinerja dalam bahasa Indonesia disebut juga prestasi kerja. Kinerja atau prestasi kerja diartikan sebagai ungkapan kemampuan yang didasari oleh pengetahuan, sikap, keterampilan dan motivasi dalam menghasilkan sesuatu.

Menurut Rivai (2005), disebutkan bahwa kinerja adalah hasil atau tingkat keberhasilan seseorang secara keseluruhan selama periode tertentu di dalam melaksanakan tugas dibandingkan dengan berbagai kemungkinan, seperti standar hasil kerja, target atau sasaran atau kriteria yang telah ditentukan terlebih dahulu dan telah disepakati bersama.

Berdasarkan beberapa pendapat para ahli diatas, dapat disimpulkan bahwa kinerja guru adalah hasil kerja yang dapat dicapai oleh seorang guru di lembaga pendidikan atau madrasah sesuai dengan tugas dan tanggung jawabnya dalam mencapai tujuan 
CENDEKIA, Vol. 12, No. 1, April 2018

p ISSN: 1978 2098; e ISSN: 2407 8557

Http://cendekia.pusatbahasa.or.id; Email: cendekiaoslo@gmail.com

Center of Language and Culture Studies, Surakarta, Indonesia

Salam, Fuad Anis \& Heriyanto, Suwiro. 2018. Pengaruh Sertifikasi Guru dan Pengembangan

Karir terhadap Kepuasan Kerja Guru Akuntansi SMA di Kota Cilegon.

Cendekia, (2018), 12(1): 23 32. DOI: 10.30957/cendekia.v12i.434.

pendidikan. Dengan kata lain, hasil kerja yang dicapai seseorang dalam melaksanakan tugas-tugas yang dibebankan kepadanya didasarkan atas kecakapan, pengalaman, dan kesungguhannya

Sertifikasi guru menurut Boyd (2007) dalam penelitiannya yang berjudul, "The Effect of Certification and Preparation on Teacher Quality," menjelaskan bahwa licensure merupakan hal penting yang harus dilakukan setelah guru melalui tahap uji coba sebagai guru selama dua tahun. Pada saat itu, guru harus menyelesaikan tes materi keilmuan dan tes keguruan, yang semuanya harus lulus dengan sempurna. Hal ini menjadi kewajiban seorang guru dalam rangka meningkatkan unjuk kerjanya. Guru yang lulus berarti ia akan mampu meningkatkan kapasitas siswa yang menjadi asuhannya.

Kane T.J. et.al (2008) dalam penelitian tentang certification and teacher effectiveness di New York City, menjelaskan bahwa sertifikasi akan mampu membedakan kinerja guru di depan kelas, efektivitas mengajr guru, dan kemampuan siswa yang diberi materi pelajaran. Sertifikat guru, juga merupakan pertanda bahwa pemegangnya mempunyai kewenangan mengajar secara legal. Di Amerika serikat, kisaran antara tahun 1999-2000 lebih dari 60\% guru tidak tersertifikasi, baru tahun 2004-2005 lebih dari 50,000 (46\%) telah disertifikasi. 34\% belum tersertifikasi, dan 20an\% guru penyetaraan.

Darling-Hammond, et. al., (2005) menyatakan bahwa sertifikasi guru akan membawa efek pada kualitas siswa. Dengan kata lain, kemampuan siswa dalam penguasaan materi pelajaran sangat ditentukan oleh kemampuan guru. Guru yang sudah tersertifikasi mampu menyampaikan materi pelajaran dengan baik, sehingga dapat dengan mudah diterima oleh siswa.

Pengembangan karir adalah proses peningkatan kemampuan kerja individu yang dicapai dalam rangka mencapai karir yang diinginkan. Dapat disimpulkan suatu pemahaman bahwa pengembangan karir adalah suatu proses berkesinambungan yang dilalui individu melalui upaya-upaya pribadi dalam rangka mewujudkan tujuan perencanaan karirnya yang disesuaikan dengan kondisi organisasi. Pengembangan karir adalah suatu yang menunjukkan adanya peningkatan peningkatan status seseorang dalam dalam suatu organisasi dalam jalur karir yang telah ditetapkan dalam organisasi yang bersangkutan (Robbins, 2007).

Bagaimanapun juga pengembangan karir masing-masing anggota dalam organisasi tentunya tidak sama, karena amat tergantung dari berbagai faktor. Titik sentral untuk meniti karir pada dasarnya terletak pada tiga hal yaitu: 1) kemampuan intelektual, 2) kemampuan dalam kepemimpinan, 3) kemampuan manajerial. Ketiga hal tersebut senantiasa dibina oleh setiap karyawan atau anggota organisasi apapun, terutama mereka yang potensial kalau ingin maju dalam karirnya. Pengembangan karir merupakan pendekatan formal yang dilakukan organisasi untuk menjamin orang-orang dalam organisasi mempunyai kualifikasi dan kemampuan serta pengalaman yang cocok ketika dibutuhkan. 
CENDEKIA, Vol. 12, No. 1, April 2018

p ISSN: 1978 2098; e ISSN: 2407 8557

Http://cendekia.pusatbahasa.or.id; Email: cendekiaoslo@gmail.com

Center of Language and Culture Studies, Surakarta, Indonesia

Salam, Fuad Anis \& Heriyanto, Suwiro. 2018. Pengaruh Sertifikasi Guru dan Pengembangan

Karir terhadap Kepuasan Kerja Guru Akuntansi SMA di Kota Cilegon.

Cendekia, (2018), 12(1): 23 32. DOI: 10.30957/cendekia.v12i.434.

\section{METODE}

Dilihat dari tujuannya, penelitian termasuk penelitian ex post facto, karena peneliti hanya menyebarkan angket penelitian tanpa memberikan perlakuan apa pun kepada subyek penelitian. Tipe penelitian ini juga dapat dimasukkan ke dalam kategori penelitian kausalitas, karena perubahan variabel bebas akan mempengaruhi dan menyebabkan terjadinya perubahan variabel terikat.

Penelitian ini dilaksanakan di SMA Kota Cilegon Provinsi Banten. Jangka waktu penelitian ini adalah cross sectional April sampai dengan Desember 2017. Populasi dalam penelitian ini adalah seluruh guru Akuntansi SMA di Kota Cilegon yang berjumlah 160 orang. Jumlah sampel yang diambil sebanyak $30 \%$ yaitu sebanyak 48 orang. Teknik yang digunakan untuk mengumpulkan data yaitu kuesioner dan dokumentasi. Teknik kuesioner dilakukan dengan memberikan pertanyaan tertulis pada responden mengenai variabel bebas dan terikat. Jenis pertanyaan yang digunakan dalam kuesioner dengan pertanyaan tertutup.

Untuk menganalisis pengaruh baik secara parsial maupun secara simultan dilakukan dalam tiga tahapan analisis yaitu analisis univariate, bivariate, dan multivariate.

\section{HASIL}

\section{Deskripsi Data}

Berdasarkan data umur responden saat mengisi instrumen diperoleh gambaran, bahwa responden berumur kurang dari 30 tahun sebanyak 12 orang (25\%), antara umur 31-40 tahun sebanyak 15 orang (31\%), antara umur 41-50 tahun sebanyak 14 orang (29\%), dan lebih dari 50 tahun sebanyak 7 orang (15\%). Jumlah guru yang hanya berpendidikan D3 sebanyak 0 orang (0\%), berpendidikan S1 sebanyak 37 orang (77\%), berpendidikan S2 sebanyak 11 orang (23\%), dan berpendidikan S3 sebanyak 0 orang $(0 \%)$.

Data yang terkumpul, juga dapat dipahami bahwa jumlah guru yang menjadi sampel penelitian, mereka yang bekerja selama 1-10 tahun sebanyak 9 orang (19\%), antara 11-20 tahun sebanyak 18 orang (38\%), antara 21-30 tahun sebanyak 16 orang (33\%), dan lebih daari 30 tahun sebanyak 5 orang (10\%).

\section{Uji Hipotesis}

Berdasarkan hasil analisis regresi satu prediktor diperoleh koefisien $\mathrm{F}$ sebesar 71.805 dengan tingkat signifikansi (p) 0,00. Tingkat signifikansi ini lebih kecil dari 0.05 dengan demikaian dapat dikatakan signifikan. Begitu juga apabila dilihat dari hasil uji t yang menunjukkan keeratan pengaruh diperoleh koefisien t sebesar 8.474 dengan signifikansi di bawah 0,05 yakni 0,000. Dengan demikian dapat dikatakan bahwa $\mathrm{H}_{0}$ ditolak dan Ha diterima. Dengan kata lain, terdapat pengaruh yang signifikan antara sertifikasi guru terhadap kepuasan kerja guru akuntanis di Kota Cilegon Provinsi Banten. Semakin baik persepsi guru terhadap sertifikasi, semakin tinggi pula kepuasan kerja guru akuntansi, dan sebaliknya, semakin buruk persepsi guru terhadap sertifikasi, 
CENDEKIA, Vol. 12, No. 1, April 2018

p ISSN: 1978 2098; e ISSN: 2407 8557

Http://cendekia.pusatbahasa.or.id; Email: cendekiaoslo@gmail.com

Center of Language and Culture Studies, Surakarta, Indonesia

Salam, Fuad Anis \& Heriyanto, Suwiro. 2018. Pengaruh Sertifikasi Guru dan Pengembangan

Karir terhadap Kepuasan Kerja Guru Akuntansi SMA di Kota Cilegon.

Cendekia, (2018), 12(1): 23 32. DOI: 10.30957/cendekia.v12i.434.

semakin rendah pula kepuasan kerja guru akuntansi di Kota Cilegon. Besarnya pengaruh variabel sertifikasi guru (X_1) terhadap kepuasan kerja guru (Y) dapat dilihat dari koefisien $\mathrm{R}^{2}$ yaitu sebesar 0.610. Dengan demikian, variabel sertifikasi guru mampu memberikan sumbangan terhadap kepuasan kerja guru sebesar 61,0\%. Sedangkan sisanya ditentukan oleh variabel lain.

Berdasarkan hasil analisis regresi satu prediktor diperoleh koefisien $\mathrm{F}$ sebesar 76.531 dengan tingkat signifikansi (p) 0,00. Tingkat signifikansi ini lebih kecil dari 0.05 dengan demikaian dapat dikatakan signifikan. Begitu juga apabila dilihat dari hasil uji $\mathrm{t}$ yang menunjukkan keeratan pengaruh diperoleh koefisien t sebesar 8.478 dengan signifikansi di bawah 0,05 yakni 0,000. Dengan demikian dapat dikatakan bahwa $\mathrm{H}_{0}$ ditolak dan Ha diterima. Dengan kata lain, terdapat pengaruh yang signifikan antara pengembangan kariri terhadap kepuasan kerja guru akuntanis di Kota Cilegon Provinsi Banten. Semakin baik persepsi guru terhadap pengembangan karir, semakin tinggi pula kepuasan kerja guru akuntansi, dan sebaliknya, semakin buruk persepsi guru terhadap pengembangan karir, semakin rendah pula kepuasan kerja guru akuntansi di Kota Cilegon. Besarnya pengaruh variabel pengembangan karir (X_2) terhadap kepuasan kerja guru (Y) dapat dilihat dari koefisien $\mathrm{R}^{2}$ yaitu sebesar 0.625 . Dengan demikian, variabel pengembangan karir mampu memberikan sumbangan terhadap kepuasan kerja guru sebesar 62,50\%. Sedangkan sisanya ditentukan oleh variabel lain.

Uji multivariat untuk menguji hiotesis ketiga. Berdasarkan hasil analisis regresi dengan dua prediktor, diperoleh Koefisien R, F, dan t sebagai berikut.

Tabel 1. Koefisien R

\begin{tabular}{|c|c|c|c|c|}
\hline Model & $\mathrm{R}$ & R Square & $\begin{array}{l}\text { Adjusted R } \\
\text { Square }\end{array}$ & $\begin{array}{c}\text { Std. Error of the } \\
\text { Estimate }\end{array}$ \\
\hline 1 & $.798^{\mathrm{a}}$ & .636 & .620 & 1.17651 \\
\hline
\end{tabular}

Tabel 2. Koefisien F

\begin{tabular}{|ll|r|r|r|r|r|}
\hline Model & & Sum of Squares & Df & Mean Square & F & Sig. \\
\hline 1 & Regression & 108.962 & 2 & 54.481 & 39.360 & $.000^{\mathrm{a}}$ \\
& Residual & 62.288 & 45 & 1.384 & & \\
& Total & 171.250 & 47 & & & \\
\hline
\end{tabular}

a. Predictors: (Constant), Pengemb_Karir_X2, Sertifikasi_Guru_X1

b. Dependent Variable: Kepuasan_kerja_Y

Sumber: Data hasil Penelitian diolah 2017 
CENDEKIA, Vol. 12, No. 1, April 2018

p ISSN: 1978 2098; e ISSN: 2407 8557

Http://cendekia.pusatbahasa.or.id; Email: cendekiaoslo@gmail.com

Center of Language and Culture Studies, Surakarta, Indonesia

Salam, Fuad Anis \& Heriyanto, Suwiro. 2018. Pengaruh Sertifikasi Guru dan Pengembangan

Karir terhadap Kepuasan Kerja Guru Akuntansi SMA di Kota Cilegon.

Cendekia, (2018), 12(1): 23 32. DOI: 10.30957/cendekia.v12i.434.

Tabel 3. Koefisien t

\begin{tabular}{|c|c|c|c|c|c|c|}
\hline \multirow{2}{*}{\multicolumn{2}{|c|}{ Model }} & \multicolumn{2}{|c|}{ Unstandardized Coefficients } & \multirow{2}{*}{$\begin{array}{c}\text { Standardized } \\
\text { Coefficients }\end{array}$} & \multirow[b]{2}{*}{$\mathrm{t}$} & \multirow[b]{2}{*}{ Sig. } \\
\hline & & B & Std. Error & & & \\
\hline \multirow[t]{3}{*}{1} & (Constant) & 14.011 & 2.403 & & 5.831 & .000 \\
\hline & Sertifikasi_Guru_X1 & .283 & .236 & .322 & 1.203 & .235 \\
\hline & Pengemb_Karir_X2 & .425 & .234 & .487 & 1.819 & .076 \\
\hline
\end{tabular}

a. Dependent Variable: Kepuasan_kerja_Y

Sumber: Data hasil Penelitian diolah 2017

Sebagaimana telah dijelaskan di kerangka berfikir dan hipotesis pada Bab III dapat diketahui bahwa:

$\mathrm{H}_{0}$ : Tidak ada pengaruh secara bersama-sam secara signifikan antara sertifikasi guru dan pengembangan karir terhadap kepuasan kerja guru akuntansi di Kota Cilegon Provinsi Banten

Ha: Terdapat pengaruh secara bersama-sam secara signifikan antara sertifikasi guru dan pengembangan karir terhadap kepuasan kerja guru akuntansi di Kota Cilegon Provinsi Banten.

Berdasarkan hasil analisis regresi dengan dua prediktor diperolah koefisien $\mathrm{F}$ sebesar 39.360 dengan signifikansi (p) sebesar 0,000 maka dapat dikatakan $\mathrm{H}_{0}$ ditolak dan $\mathrm{H}_{\mathrm{a}}$ diterima. Tingkat pengaruh antara variabel sertifikasi guru (X_1) dan pengembangan karir (X_2) terhadap kepuasan kerja guru yaitu sebesar 5.83 dengan tingkat signifikansi 0.000. dengan demikian dapat dipahami bahwa terdapat pengaruh bersama-samaa yang signifikan antara sertifikasi guru dan pengembangan karir terhadap kepuasan kerja guru Akuntansi di Kota Cilegon Provinsi Banten.

Sumbangan kedua variabel tersebut dapat dilihat pada koefisien R Square yaitu sebesar $63.6 \%$. dengan demikian variabel sertifikasi guru dan pengembangan karir memberikan kontribusi terhaap kepuasan kerja guru sebesar $63,6 \%$ dan sisanya sebesar $36,4 \%$ ditentukan oleh variabel lain yang tidak diteliti dalam penelitian ini.

\section{BAHASAN}

Berdasarkan hasil analisis data sebagaimana telah dilakukan di atas, dapat dilakukan pembahasan sesuai tema-tema kegiatan.

Pertama, berdasarkan hasil analisis data dapat diketahui bahwa terdapat pengaruh yang sifinifikan antara sertifikasi guru dengan kepuasan kerja guru akuntansi di Kota Cilegon. Semakin baik persepsi guru terhadap sertifikasi, maka semakin tinggi pula kepuasan kerja guru. Sebliknya, semakin buruk persepsi guru terhadap sertifikasi guru, maka semakin rendah pula kepuasan kerja guru akuntansi.

Hasil penelitian ini pada dasarnya sejalan dengan temuan penelitian yang dilakukan oleh Muhajir (2011) dalam melakukan penelitian menunjukkan bahwa 
CENDEKIA, Vol. 12, No. 1, April 2018

p ISSN: 1978 2098; e ISSN: 2407 8557

Http://cendekia.pusatbahasa.or.id; Email: cendekiaoslo@gmail.com

Center of Language and Culture Studies, Surakarta, Indonesia

Salam, Fuad Anis \& Heriyanto, Suwiro. 2018. Pengaruh Sertifikasi Guru dan Pengembangan

Karir terhadap Kepuasan Kerja Guru Akuntansi SMA di Kota Cilegon.

Cendekia, (2018), 12(1): 23 32. DOI: 10.30957/cendekia.v12i.434.

pengakuan kompetensi profesional guru dalam bentuk pemberian sertifikasi mampu meningkatkan kepuasan kerja guru. Analisis hubungan antar variabel menunjukkan bahwa pada taraf signifikan $0,05 \%$ atau taraf kepercayaan $95 \%$

Kedua, berdasarkan hasil analisis data dapat diketahui bahwa terdapat pengaruh yang sifinifikan antara pengembangan karir dengan kepuasan kerja guru akuntansi di Kota Cilegon. Semakin baik pengembangan karir, maka semakin tinggi pula kepuasan kerja guru. Sebliknya, semakin buruk pengembangan karir, maka semakin rendah pula kepuasan kerja guru akuntansi

Hasil penelitian ini pada dasarnya sejalan dengan temuan penelitian yang dilakukan oleh Pearson (2008) saat melakukan penelitian tentang Career development, job satisvaction, and career commitment menyimpulkan bahwa pengembangan karir berpengaruh signifikan terhadap kepuasan kerja. Pengembangan karir sebagai variabel prediktor terhadap tingginya kepuasan kerja.

Hasil penelitian ini juga menguatkan temuan Kalayar dan Ozmuraf, (2009), yang melakukan riset berkaitan dengan The Effect of Individual Career Planning on Job Satisfaction: A comparative study on academic and administrative staff. Penelitian ini menyimpulkan bahwa perencanaan karir oleh masing-masing individu berpengaruh signifikan terhadap kepuasan kerja dengan koefisien $r$ sebesar 0,269 dengan $p$ (signifikansi) 0,000. Tidak ada perbedaan antara tenaga akademik dan administrasi baik dalam perencanaan karir maupun kepuasan kerja.

Penelitian ini juga sejalan dengan tumah Djestawana, (2009) yang meneliti tentang pengaruh pengembangan organisasi, kepemimpinan, pengembangan karir terhadap kepuasan kerja dan implikasinya pada kinerja pegawai puskesmas kota Denpasar Provinsi Bali, menyimpulkan bahwa pengemangan karir berpengaruh terhadap kepuasan kerja. Pengambangan karir berkontribusi sebesar 0,081) terhadap kepuasan kerja. Metode yang digunakan untuk univariat adalah confirmatory factor analysis, metode untuk bivariat dengan kanonical correlation, dan analisis multivariate dengan structural equation model (SEM), dengan program komputer AMOS. Sampel yang digunakan sebanyak 324 orang (total populasi).

Ketiga, berdasarkan hasil analisis data dapat diketahui bahwa terdapat pengaruh bersama-sama secara sifinifikan antara sertifikasi guru dan pengembangan karir terhadap kepuasan kerja guru akuntansi di Kota Cilegon. Semakin baik persepsi guru terhadap sertifikasi dan pengembangan karir, maka semakin tinggi pula kepuasan kerja guru. Sebliknya, semakin buruk persepsi guru terhadap sertifikasi guru dan pengembangan karir, maka semakin rendah pula kepuasan kerja guru akuntansi.

Hasil penelitian ini pada dasarnya sejalan dengan temuan penelitian yang dilakukan oleh Almaidah (2013) menyimpulkan bahwa sertifikasi guru dan pengembangan karir secara bersama-sama mempengaruhi tingkat kepuasan kerja guru di SMA N 1 Natar Kabupaten Lampung Selatan dengan $\mathrm{R}^{2}$ sebesar 0,64. Sertifikasi mempunyai pengaruh yang lebih besar disbanding pengembangan karir dalam meningkatkan kepuasan kerja. 
CENDEKIA, Vol. 12, No. 1, April 2018

p ISSN: 1978 2098; e ISSN: 2407 8557

Http://cendekia.pusatbahasa.or.id; Email: cendekiaoslo@gmail.com

Center of Language and Culture Studies, Surakarta, Indonesia

Salam, Fuad Anis \& Heriyanto, Suwiro. 2018. Pengaruh Sertifikasi Guru dan Pengembangan

Karir terhadap Kepuasan Kerja Guru Akuntansi SMA di Kota Cilegon.

Cendekia, (2018), 12(1): 23 32. DOI: 10.30957/cendekia.v12i.434.

Hasil penelitian ini juga sesuai dengan temuan Siti Kalimah (2014) dalam melakukan tentang sertifikasi guru menyimpulkan bahwa sertifikasi guru dan pengembangan karir secara bersama-sama mampu mempengaruhi secara signifikan terhadap tingkat kepuasan kerja guru di SMP N 2 Grabag Kabupaten Purworejo Jawa tengah. Sertifikasi guru mempunyai pengaruh yang lebih besar dibanding pengembangan karir dalam meningkatkan kepuasan kerja. Namun perbedaan itu tidak terlalu besar.

\section{SIMPULAN}

Berdasarkan hasil penelitian dan pembahasan sebagaimana telah diuraikan pada bab sebelumnya dapat disimpulkan:

1. Terdapat pengaruh yang sifinifikan antara sertifikasi guru dengan kepuasan kerja guru akuntansi di Kota Cilegon. Semakin baik persepsi guru terhadap sertifikasi, maka semakin tinggi pula kepuasan kerja guru. Sebliknya, semakin buruk persepsi guru terhadap sertifikasi guru, maka semakin rendah pula kepuasan kerja guru akuntansi di Kota Cilegon.

2. Terdapat pengaruh yang sifinifikan antara pengembangan karir dengan kepuasan kerja guru akuntansi di Kota Cilegon. Semakin baik pengembangan karir, maka semakin tinggi pula kepuasan kerja guru. Sebliknya, semakin buruk pengembangan karir, maka semakin rendah pula kepuasan kerja guru akuntansi di Kota Cilegon.

3. Terdapat pengaruh bersama-sama secara sifinifikan antara sertifikasi guru dan pengembangan karir terhadap kepuasan kerja guru akuntansi di Kota Cilegon. Semakin baik persepsi guru terhadap sertifikasi dan pengembangan karir, maka semakin tinggi pula kepuasan kerja guru. Sebliknya, semakin buruk persepsi guru terhadap sertifikasi guru dan pengembangan karir, maka semakin rendah pula kepuasan kerja guru akuntansi di Kota Cilegon.

\section{REFERENSI}

Almaidah (2013) Pengaruh kompetensi guru dan pengembangan karir terhadap kepuasan kerja guru di SMA N 1 Natar Kabupaten Lampung Selatan, Jurnal Mainstream, 4(1):34-46.

Boyd, D., Goldhaber, H., \& Wyckoff, J. (2007). "The effect of certification and preparation on teacher quality." The Future of Children, 1(1):1-12. http://www.jstor.org/ pdf

Darling-Hammond, L., Holtzman, D., Gatlin, S.J., \& Heilig, J. V. (2005). Does teacher preparation matter? Evidence about teacher certification, Teach for America, and teacher effectiveness. Education Policy Analysis Archives, 13(42). http://epaa.asu.edu/epa//v13n42/. 
CENDEKIA, Vol. 12, No. 1, April 2018

p ISSN: 1978 2098; e ISSN: 2407 8557

Http://cendekia.pusatbahasa.or.id; Email: cendekiaoslo@gmail.com Center of Language and Culture Studies, Surakarta, Indonesia

Salam, Fuad Anis \& Heriyanto, Suwiro. 2018. Pengaruh Sertifikasi Guru dan Pengembangan Karir terhadap Kepuasan Kerja Guru Akuntansi SMA di Kota Cilegon. Cendekia, (2018), 12(1): 23 32. DOI: 10.30957/cendekia.v12i.434.

Djestawana, I Gusti Gede, (2009), Pengaruh Pengembangan Organisasi, Kepemimpinan, Pengembangan Karir terhadap Kepuasan Kerja dan Implikasinya pada Kinerja Pegawai Puskesmas Kota Denpasar Provinsi Bali, Disertasi tidak dipublikasikan, Jakara, PPS Program Doktor Ilmu Ekonomi, UPI YAI.

Kalayar, Murat dan Metin Ozmuraf, (2009), "The Effect of Individual Career Planning on Job Satisfaction: A comparative study on academic and administrative staff," The Journal of Faculty of Economics and Administrative science. 14(1):13-24.

Kane T.J. et.al (2008) "What does certification tell us about teacher effectiveness? Evidence from New York City," Economics of Education Review, 27: 615-631.

Muhajir, Muhammad. 2011. "Hubungan antara Keefektifan Sertifikasi Guru, Kompetensi Profesional, Semangat Kerja, dan Budaya Mutu dengan Kinerja Guru pada Sekolah Dasar Negeri di Kabupaten Jember.” Disertasi, Program Studi Manajemen Pendidikan Program Pascasarjana, Universitas Negeri Malang

Pearson, Cecil, (2008) "Career Development, Job Satisfaction, and Career Commitment: Evidence from the Singaporean Hospitality Industry," Journal Business, Institute of Management Technology, 12(2):239-254.

Riva'i, Veithzal (2005) Manajemen Sumberdaya Manusia untuk Perusahaan: dari Teori ke Praktik. Jakarta: Radja Grapindo Persada

Robbins, Stephen dan Timothy A. Judge (2008) Organization Behavior. diterjemahkan oleh Angelica dkk, Jakarta: Salemba Empat

Kalimah, Siti (2014) Hubungan sertifikasi guru dan pengembangan karir terhadap tingkat kepuasan kerja guru di SMP N 2 Grabag Kabupaten Purworejo Jawa tengah, Jurnal Ilmu Pendidikan, 2(1): 1-12. 
CENDEKIA, Vol. 12, No. 1, April 2018

p ISSN: 1978 2098; e ISSN: 2407 8557

Http://cendekia.pusatbahasa.or.id; Email: cendekiaoslo@gmail.com

Center of Language and Culture Studies, Surakarta, Indonesia

Salam, Fuad Anis \& Heriyanto, Suwiro. 2018. Pengaruh Sertifikasi Guru dan Pengembangan

Karir terhadap Kepuasan Kerja Guru Akuntansi SMA di Kota Cilegon.

Cendekia, (2018), 12(1): 23 32. DOI: 10.30957/cendekia.v12i.434. 